\title{
Cancer gene panel analysis of cultured circulating tumor cells and primary tumor tissue from patients with breast cancer
}

\author{
EUNJOO HWANG ${ }^{1}$, JI-HYUN UH ${ }^{1}$, HYE SEON LEE ${ }^{1}$, CHAM HAN LEE $^{1}$, SOO JEONG LEE ${ }^{1}$, SEI HYUN AHN ${ }^{2}$, \\ BYUNG HO SON ${ }^{2}$, JONG WON LEE ${ }^{2}$, JONG HAN YU ${ }^{2}$, NAK-JUNG KWON ${ }^{3}$, WOO CHUNG LEE ${ }^{3}$, \\ KAP-SEOK YANG ${ }^{3}$, SUNG HO CHOI ${ }^{1}$, MYOUNG SHIN KIM ${ }^{1}$, JINSEON LEE ${ }^{1}$ and BYUNG HEE JEON ${ }^{1}$ \\ ${ }^{1}$ Cytogen Incorporated, Songpa, Seoul 138-961; ${ }^{2}$ Department of Surgery, Asan Medical Center, College of Medicine, \\ University of Ulsan, Songpa, Seoul 138-736; ${ }^{3}$ Macrogen Incorporated, Geumcheon, Seoul 153-781, Republic of Korea
}

Received August 7, 2015; Accepted December 16, 2016

DOI: $10.3892 / 01.2017 .6077$

\begin{abstract}
Although numerous effective therapies have improved the survival rate of patients with breast cancer, a number of patients present with tumor recurrence and metastasis. A liquid biopsy of circulating tumor cells (CTC) is a non-invasive method to obtain tumor cells and may be used as substitute for a tumor tissue biopsy. The present study focuses on determining whether CTC culture is an optimal method of obtaining sufficient amounts of CTCs for molecular analysis. The current study demonstrates a method of isolating and culturing CTCs from patients with breast cancer and the construction of a molecular profile of cultured cells using the Ion AmpliSeq Cancer Gene Panel V2. Gene mutations that were observed in cultured CTCs were compared with those observed in primary tumor tissues. CTCs were isolated and cultured from the blood of six patients with breast cancer. Mutations from the Catalogue Of Somatic Mutation In Cancer (COSMIC) were detected in Platelet-Derived Growth Factor Receptor Alpha, MET (also known as Hepatocyte Growth Factor Receptor), Phosphatase and Tensin Homolog, Harvey Rat Sarcoma Viral Oncogene Homolog, SWI/SNF Related, Matrix Associated, Actin Dependent Regulator of Chromatin Subfamily B Member 1, Cyclin Dependent Kinase Inhibitor $2 \mathrm{~A}$ and MutL Homolog 1 genes in 5/6 samples. A comparison between mutations detected in cultured CTCs and mutations detected in primary tumor tissues demonstrated that a large number of mutations that were identified in CTCs were also detected in primary tumor tissues. The results from the current study describe a novel cell culture approach that may be used to obtain an optimal number of CTCs for molecular analysis.
\end{abstract}

Correspondence to: Dr Byung Hee Jeon, Cytogen Incorporated, Garden 5 Works, A-616, 52 Chungmin Street, Songpa, Seoul 138-961, Republic of Korea

E-mail: bhjeon@cytogenlab.com

Key words: breast cancer, circulating tumor cells, culture, cancer gene panel analysis, liquid biopsy
This novel approach is able to be used as a tool for liquid biopsy during breast cancer treatment.

\section{Introduction}

Circulating tumor cells (CTCs) were first described in 1869 (1). CTCs, which are shed from primary tumor tissue (2), circulate in the bloodstream and promote metastasis $(3,4)$. CTCs have molecular characteristics that are also exhibited by the primary tumor tissue $(5,6)$; therefore, it may be possible to evaluate drug sensitivity and resistance and predict patient prognosis following therapy using the CTCs obtained by liquid biopsy $(7,8)$.

Breast cancer mortality is the fifth highest among all cancer types and is the highest within the forms of cancer that affect only females (9). Although effective therapies targeting hormone receptors and human epidermal growth factor receptor 2 expression have improved survival rates, tumor recurrence and metastasis occur in a number of patients $(10,11)$. Recurrent tumors and metastases have genetic characteristics that differ from those of the original tumor and, therefore, alternative therapies may be required for these tumors (12). CTCs from patients with breast cancer may be able to indicate tumor recurrence and metastasis (13), predict survival rate (14) and predict which therapy may be optimal $(15,16)$.

A previous study demonstrated a correlation between the number of CTCs and breast cancer recurrence or survival rate (17). Another previous study indicated that the number of CTCs detected during therapy may be a predictive tool for progression-free and overall survival rate (18). Additionally, genomic profiles of CTCs may be used to predict therapeutic prognoses, identify an optimal therapy and analyze the molecular variation of the tumor during treatment (19). However, genomic analyses of CTCs are challenging to perform due to the rarity of these cells (20). In the present study, live, intact CTCs were isolated by size and were subsequently cultured to obtain sufficient quantities of cells for genomic analysis.

\section{Materials and methods}

Clinical information of patients. A total of six patients with breast cancer from the Asan Medical Center (Seoul, Korea) 
were included in the present study. The median age was 44 years (range, 37-47). The stages of the cancer were evaluated using the Tumor, Node and Metastasis (TNM) system based on the recommendations of the 7th American Joint Committee on Cancer (21). All blood samples, tumor tissues and medical data used were anonymous, to ensure patient confidentiality. The protocol that was used for the current study was ethically approved by the institutional review board of ASAN Medical Center (clearance no. 2013-1048).

Blood collection and CTC enrichment process. Blood (10 $\mathrm{ml})$ from each patient was obtained, stored in acid citrate dextrose tubes and processed within $4 \mathrm{~h}$. The CTC culture kit (\#CIKC10; Cytogen, Inc., Seoul, Korea) was used to isolate CTCs from blood samples for culture. Briefly, density gradient centrifugation was performed at $400 \mathrm{x} \mathrm{g}$ for $30 \mathrm{~min}$ at room temperature using the blood samples, and the fraction containing peripheral blood mononuclear cells was diluted with a dilution buffer from the kit. Diluted cell suspensions were filtered using a high-density microporous (HDM) chip (Cytogen, Inc.) (22) and the cells retrieved from the HDM chip were cultured.

Primary culture of CTCs. The CTCs that were isolated were washed with PBS and cultured in 6-well Costar ${ }^{\circledR}$ Ultra-Low Attachment plates (Costar ${ }^{\circledR}$; Corning Korea Company, Ltd., Seoul, Korea) containing mesenchymal stem cell growth medium (MSCGM ${ }^{\mathrm{TM}}$, human Mesenchymal Stem Cell Growth BulletKit ${ }^{\mathrm{TM}}$ Medium and Supplements; Lonza Group, Basel, Switzerland) at $37^{\circ} \mathrm{C}$, in an atmosphere containing $5 \%$ $\mathrm{CO}_{2}$. Following 16-18 days of culture, cells were fixed in $4 \%$ paraformaldehyde on microscope slides, to be used in the immunofluorescence staining protocol. Cell images were taken every other day under light microscopy (Eclipse TS 100; Nikon Corporation, Tokyo, Japan). Cell pellets were stored at $-80^{\circ} \mathrm{C}$ prior to cancer gene panel analysis.

Immunofluorescence staining. The fixed cells on microscope slides were incubated with $0.2 \%$ Triton X-100 in PBS for $10 \mathrm{~min}$ at room temperature and subsequently treated with $0.3 \%$ hydrogen peroxide for $30 \mathrm{~min}$ at room temperature. Following blocking with $1 \%$ bovine serum albumin (cat. no. SH30574.02; GE Healthcare Life Sciences, Chalfont, UK) in PBS for 30 min, the cells were incubated with mouse anti-epithelial cell adhesion molecule (EpCAM) antibody (dilution, 1:200, cat. no. 2929; CST Biological Reagents Company Limited, Shanghai, China) at room temperature for $1 \mathrm{~h}$. EpCAM signals were amplified with the Tyramide Signal Amplification $^{\text {TM }}$ kit (cat. no. T20922; Thermo Fisher Scientific, Inc., Waltham, MA, USA) according to the manufacturer's protocol. The slides were mounted using Fluoroshield ${ }^{\text {TM }}$ with DAPI (ImmunoBioScience Corp., Mukilteo, WA, USA). Stained cells were captured on a Nikon Eclipse Ti fluorescence microscope equipped with a 200X objective.

Whole genome amplification. The cellular DNA was obtained from cell pellets that were stored at $-80^{\circ} \mathrm{C}$ and were amplified using the REPLI-g Single Cell kit (Qiagen GmbH, Hilden, Germany) according to the manufacturer's protocol. Briefly, cell pellets were resuspended with the denaturation buffer and incubated at $65^{\circ} \mathrm{C}$ for $10 \mathrm{~min}$. Following the addition of the stop
Table I. Clinical characteristics of patients with breast cancer, including immunofluorescence staining analysis of EpCAM-positive cells.

\begin{tabular}{lcccc}
\hline & & & \multicolumn{2}{c}{ No. of cultured cells } \\
\cline { 4 - 5 } Patient & Age, & $\begin{array}{c}\text { AJCC/ } \\
\text { TNM } \\
\text { ID }\end{array}$ & $\begin{array}{c}\text { Total } \\
\text { no. of } \\
\text { cells }\end{array}$ & $\begin{array}{c}\text { No. of } \\
\text { EpCAM+ } \\
\text { cells, \% }\end{array}$ \\
\hline AMC-15-01 & 47 & IIA & $4.0 \times 10^{5}$ & 34.92 \\
AMC-15-02 & 38 & IIA & $5.0 \times 10^{5}$ & 53.74 \\
AMC-15-03 & 43 & IIA & $5.0 \times 10^{5}$ & 53.76 \\
AMC-15-04 & 51 & IIB & $5.2 \times 10^{5}$ & 41.20 \\
AMC-15-05 & 37 & IIIC & $8.3 \times 10^{5}$ & 86.54 \\
AMC-15-06 & 46 & IIB & $4.5 \times 10^{5}$ & 86.14 \\
\hline
\end{tabular}

AJCC/TNM, the 7th American Joint Committee on Cancer/Tumor Node Metastasis; ID, identification; EpCAM, epithelial cell adhesion molecule; EpCAM+, cells positive for epithelial cell adhesion molecule staining; AMC, Asan Medical Center.

solution, denatured DNA samples were added to REPLI-g single cell DNA polymerase and the reaction buffer. This mixture was incubated at $30^{\circ} \mathrm{C}$ for $8 \mathrm{~h}$ and subsequently at $65^{\circ} \mathrm{C}$ for $3 \mathrm{~min}$.

Genomic DNA extraction from primary tumor tissues. The genomic DNA was extracted from 5- $\mu \mathrm{m}$ sections of formalin-fixed, paraffin-embedded (FFPE) primary tumor tissues. H\&E-stained FFPE slides were initially examined by a pathologist (Asan Medical Center) to validate the presence of tumor cells. DNA that was present in the tumor cells was extracted using the Gentra ${ }^{\circledR}$ Puregene ${ }^{\circledR}$ DNA Isolation kit (Qiagen $\mathrm{GmbH}$ ) according to the manufacturer's protocol.

Ion AmpliSeq ${ }^{T M}$ Cancer Panel analysis. Genomic mutations were detected using the Ion AmpliSeq ${ }^{\mathrm{TM}}$ Cancer Hotspot Panel v2 (Thermo Fisher Scientific, Inc.). Briefly, the genomic DNA was amplified using the REPLI-g Amplification kit (Qiagen GmbH) and the amplicons were purified using the Agencourt AM-Pure XP kit (Beckman Coulter, Inc., Brea, CA, USA), followed by end repair and ligation using the Ion Xpress ${ }^{\mathrm{TM}}$ Barcode Adapters kit (cat. no. 4471250; Thermo Fisher Scientific, Inc.). Subsequent end-repair and ligation was performed with Ion Xpress Barcode Adapters (Thermo Fisher Scientific, Inc.). The median fragment size and the concentration of the final library were determined using a BioAnalyzer equipped with a High-Sensitivity Chip (Agilent Technologies GmbH, Waldbronn, Germany). Subsequently the library was diluted to $10 \mathrm{pM}$ with TE using a low-Tris EDTA buffer, $5 \mu \mathrm{l}$ of the library was used for emulsion polymerase chain reaction (PCR) using the Onetouch ${ }^{\mathrm{TM}}$ reagent kit (Invitrogen; Thermo Fisher Scientific, Inc.). The following cycling conditions were used: $80^{\circ} \mathrm{C}$ for $3 \mathrm{~min} ; 18$ cycles of $99^{\circ} \mathrm{C}$ for $20 \mathrm{sec}, 58^{\circ} \mathrm{C}$ for $30 \mathrm{sec}, 72^{\circ} \mathrm{C}$ for $60 \mathrm{sec}, 99^{\circ} \mathrm{C}$ for $20 \mathrm{sec}$, $56^{\circ} \mathrm{C}$ for $30 \mathrm{sec}$, and $70^{\circ} \mathrm{C}$ for $60 \mathrm{sec}$; and 10 cycles of $99^{\circ} \mathrm{C}$ for $20 \mathrm{sec}$, and $58^{\circ} \mathrm{C}$ for elongated duration from $3 \mathrm{~min}$ to $20 \mathrm{~min}$, with the thermocycler lid heated to $85^{\circ} \mathrm{C}$. The products of these emulsion PCR reactions were enriched using Dynabeads ${ }^{\circledR}$ 
A

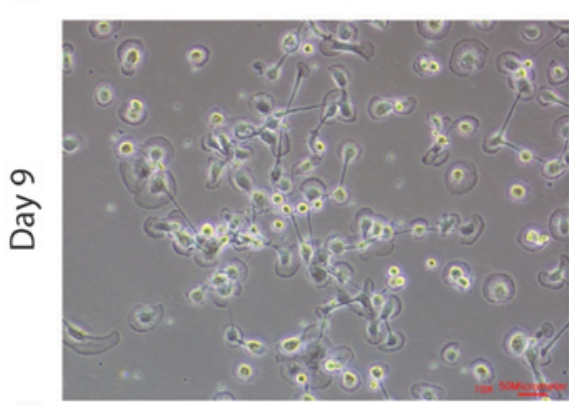

C

m

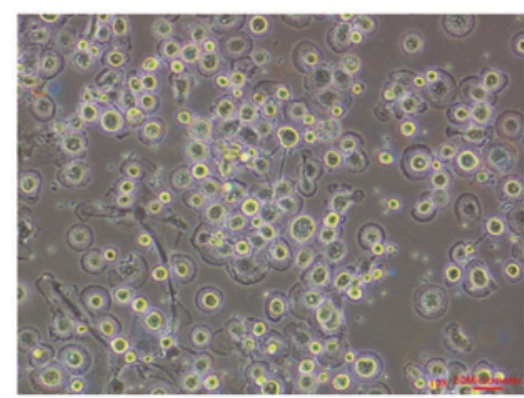

B

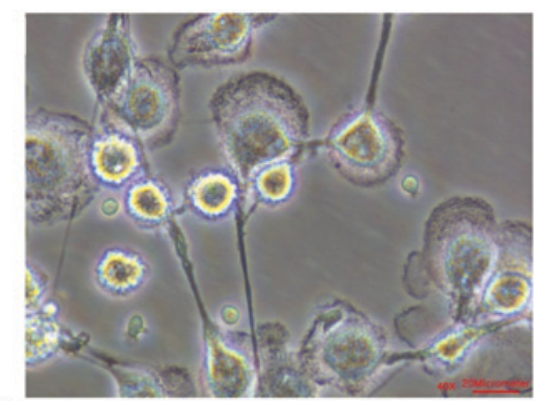

D

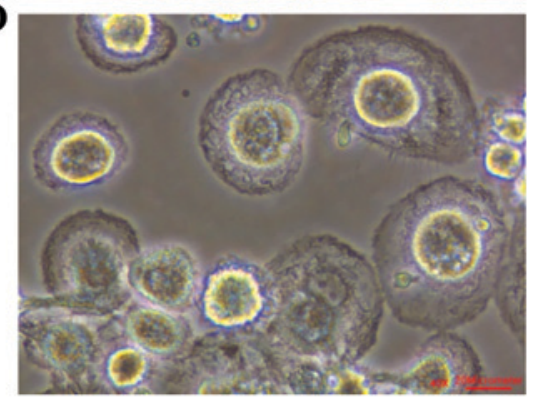

Figure 1. Representative microscopic images of CTC cultures at (A and B) day 9 and (C and D) day 13. (A and C) magnification, x100; (B and D) magnification, x400. CTCs, circulating tumor cells.

A
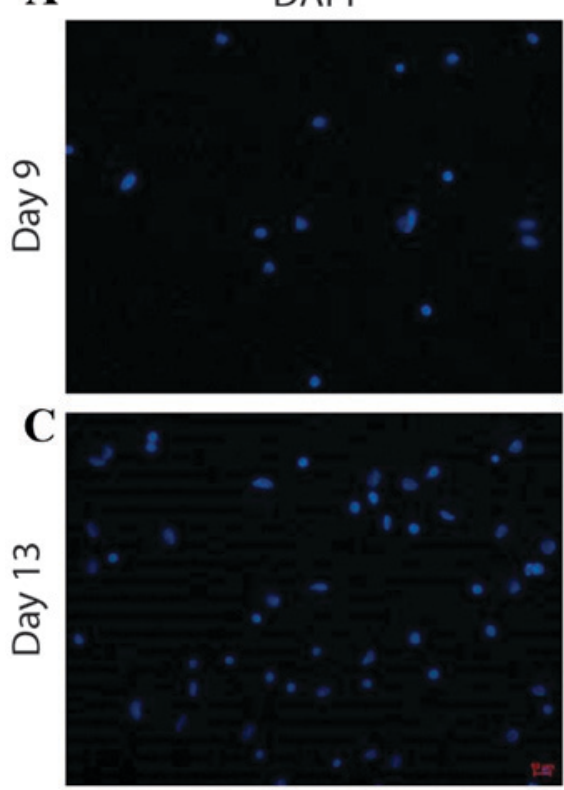

B

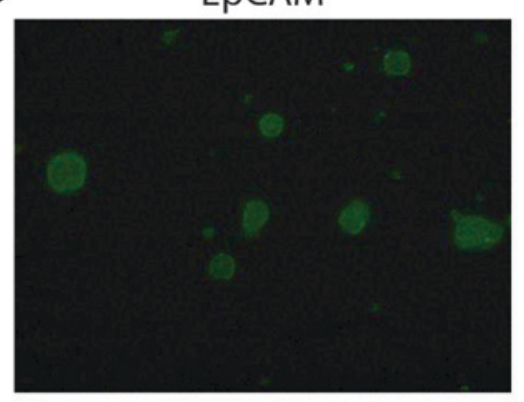

$\mathbf{D}$

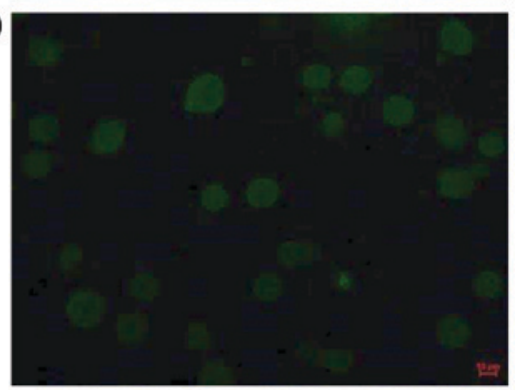

Figure 2. Immunofluorescence staining of cultured CTCs for DAPI and EpCAM at (A and B) day 9 and (C and D) day 13. Magnification, x200. CTCs, circulating tumor cells; EpCAM, epithelial cell adhesion molecule.

MyOne ${ }^{\mathrm{TM}}$ Streptavidin C1 beads (Invitrogen; Thermo Fisher Scientific, Inc.). The final enriched ion spheres were mixed with sequencing primers and polymerase and loaded onto five Ion 316 chips. Base calls were generated using Torrent Suite 3.0 software (Thermo Fisher Scientific, Inc.) with tmap-f3 and maintained on the Ion Torrent server for further analysis. Base calling was generated using Torrent Suite software (version 3.0; Thermo Fisher Scientific, Inc.) with tmap-f3 indexing. BAM and FASTQ alignment files were generated based on the base calling results and were used for variant calling, including single nucleotide polymorphisms and insertions/deletions.

\section{Results}

Expansion of CTCs via cell culture. CTCs from six patients with breast cancer were cultured to obtained optimal numbers of cells for characterization. During the first nine days of culture, cells were attached or suspended as single cells (Fig. 1A and B). The cells were cultured until there were between $4 \times 10^{5}$ and $8 \times 10^{5}$ cells (Fig. 1C; Table I) and the attached cells exhibited cell membrane ruffling (Fig. 1D). The presence of cell membrane ruffling demonstrated the selective expansion of epithelial cells and improved cell motility. 
Table II. Ion AmpliSeq Cancer Panel V2 of cultured CTCs from patients with breast cancer.

\begin{tabular}{|c|c|c|c|c|}
\hline Patient ID & Gene ID & Type of mutation & AA mutation & COSMIC number \\
\hline \multirow[t]{5}{*}{ AMC-15-01 } & PDGFRA & SNP & N659K & COSM22414 \\
\hline & $M E T$ & SNP & Unknown & COSM710 \\
\hline & PTEN & INS & N323fs*2 & COSM23626 \\
\hline & PTEN & INS & T321fs*3 & COSM4994 \\
\hline & PTEN & INS & N323fs*2 & COSM4990 \\
\hline \multirow[t]{3}{*}{ AMC-15-02 } & PDGFRA & SNP & V824V & COSM22413 \\
\hline & $H R A S$ & SNP & $\mathrm{H} 27 \mathrm{H}$ & COSM249860 \\
\hline & SMARCB1 & SNP & Unknown & COSM1090 \\
\hline \multirow[t]{3}{*}{ AMC-15-03 } & PDGFRA & SNP & V824V & COSM22413 \\
\hline & $H R A S$ & SNP & $\mathrm{H} 27 \mathrm{H}$ & COSM249860 \\
\hline & SMARCB1 & SNP & Unknown & COSM1090 \\
\hline AMC-15-04 & & & N/A & \\
\hline AMC-15-05 & $C D K N 2 A$ & SNP & H66R & COSM14253 \\
\hline \multirow[t]{3}{*}{ AMC-15-06 } & MLH1 & SNP & V384D & COSM26085 \\
\hline & $M E T$ & SNP & Unknown & COSM710 \\
\hline & $H R A S$ & SNP & $\mathrm{H} 27 \mathrm{H}$ & COSM249860 \\
\hline
\end{tabular}

AA, amino acid; SNP, single nucleotide polymorphism; INS, insertion; N/A, not applicable; CTCs, circulating tumor cells; AMC, Asan Medical Center; ID, identification; COSMIC, Catalogue of Somatic Mutations in Cancer; $f s^{*}$, frameshift of; PDGFRA, platelet-derived growth factor receptor $\alpha$; MET, hepatocyte growth factor receptor; PTEN, phosphatase and tensin homolog; HRAS, Harvey rat sarcoma viral oncogene homolog; SMARCB1, switch/sucrose non-fermentable-related, matrix-associated, actin-dependent regulator of chromatin subfamily B member 1; CDKN2A, cyclin-dependent kinase inhibitor 2A; MLH1, mutation L homolog 1 gene.

Table III. Comparison of COSMIC mutations detected in primary tumor tissue with those detected in cultured CTCs from patient AMC-15002 with breast cancer.

\begin{tabular}{lllll}
\hline Tissue & Gene ID & Mutation type & AA mutation & COSMIC number \\
\hline Primary tissue & NOTCH1 & DEL & V1578delV & COSM13047 \\
& HRAS & SNP & H27H & COSM249860 \\
& TP53 & SNP & H193Y & COSM10672 \\
CTCs & PDGFRA & SNP & V824V & COSM22413 \\
& HRAS & SNP & H27H & COSM249860 \\
& SMARCB1 & SNP & Unknown & COSM1090 \\
\hline
\end{tabular}

AA, amino acid; DEL, deletion; SNP, single nucleotide polymorphism; ID, identification; COSMIC, Catalogue of Somatic Mutations in Cancer; PDGFRA, platelet-derived growth factor receptor $\alpha$; HRAS, Harvey rat sarcoma viral oncogene homolog; SMARCB1, switch/sucrose non-fermentable-related, matrix-associated, actin-dependent regulator of chromatin subfamily B member 1; NOTCH1, Notch homolog 1, translocation-associated; TP53, tumor protein 53; CTCs, circulating tumor cells; del, deletion.

CTC characterization. Following 16 to 18 days of cell culture, immunofluorescence staining was performed for EpCAM, an epithelial cell marker, to evaluate the proportion of cultured cells that were CTCs (Fig. 2). The percentage of EpCAM-positive cells in the samples from patients with breast cancer ranged from $35-86 \%$ (Table I), which suggested that CTCs may be the predominantly proliferating cells.

Cancer gene panel analysis. COSMIC mutations in Platelet-Derived Growth Factor Receptor Alpha (PDGFRA), MET (also known as Hepatocyte Growth Factor Receptor),
Phosphatase and Tensin Homolog (PTEN), Harvey Rat Sarcoma Viral Oncogene Homolog (HRAS), SWI/SNF Related, Matrix Associated, Actin Dependent Regulator of Chromatin Subfamily B Member 1 (SMARCB1), Cyclin Dependent Kinase Inhibitor $2 \mathrm{~A}(C D K N 2 A)$ and MutL Homolog 1 genes (MLH1) genes were detected in 5/6 samples of cultured CTCs (Table II). To evaluate whether the cultured CTCs maintained genomic profiles that were similar to those of the primary tumor tissues, mutations were analyzed in cultured CTCs and compared with those detected in primary tumor tissues. In the samples obtained from patient AMC-15-02, an identical 
Table IV. Comparison of Ion AmpliSeq Cancer Panel V2 between primary tumor tissue and cultured CTCs from patient AMC-15002 with breast cancer.

\section{A, Primary tumor tissue}

\begin{tabular}{lclc}
\hline $\begin{array}{l}\text { Gene } \\
\text { ID }\end{array}$ & $\begin{array}{c}\text { Type of } \\
\text { mutation }\end{array}$ & $\begin{array}{c}\text { Allele } \\
\text { source }\end{array}$ & $\begin{array}{c}\text { COSMIC } \\
\text { number }\end{array}$ \\
\hline ERBB4 & SNP & Novel & - \\
VHL & SNP & Novel & - \\
FGFR3 & SNP & Novel & - \\
PDGFRA & SNP & Novel & - \\
APC & SNP & Novel & - \\
CSF1R & MNP & Novel & - \\
NOTCH1 & DEL & Hotspot & COSM13047 \\
RET & SNP & Novel & - \\
HRAS & SNP & Hotspot & COSM249860 \\
ATM & INS & Novel & - \\
FLT3 & SNP & Novel & - \\
TP53 & SNP & Novel & - \\
TP53 & SNP & Hotspot & COSM10672 \\
TP53 & SNP & Novel & - \\
\hline
\end{tabular}

\section{B, Cultured CTCs}

\begin{tabular}{lllc}
\hline ALK & SNP & Novel & - \\
ERBB4 & SNP & Novel & - \\
FGFR3 & SNP & Novel & - \\
PDGFRA & SNP & Novel & - \\
PDGFRA & SNP & Hotspot & COSM22413 \\
APC & SNP & Novel & - \\
CSF1R & MNP & Novel & - \\
EGFR & SNP & Novel & - \\
NOTCH1 & SNP & Novel & - \\
RET & SNP & Novel & - \\
HRAS & SNP & Hotspot & COSM249860 \\
FLT3 & SNP & Novel & - \\
TP53 & SNP & Novel & - \\
STK11 & SNP & Novel & - \\
SMARCB1 & SNP & Hotspot & COSM1090 \\
\hline
\end{tabular}

SNP, single nucleotide polymorphism; MNPs, multinucleotide; INS, insertion; DEL, deletion; CTCs, circulating tumor cells; AMC, Asan Medical Center; ID, identification; COSMIC, Catalogue of Somatic Mutations in Cancer; ALK, anaplastic lymphoma receptor tyrosine kinase; ERBB4, Erb-B2 receptor tyrosine kinase 4; VHL, von Hippel-Lindau tumor suppressor; FGFR3, fibroblast growth factor receptor 3; PDGFRA, platelet-derived growth factor receptor $\alpha$; APC, adenomatosis polyposis cell; CSFR1, colony stimulating factor 1; NOTCH1, Notch homolog 1, translocation-associated; RET, rearranged during transfection; HRAS, Harvey rat sarcoma viral oncogene homolog; ATM, ataxia telangiectasia mutated; FLT3, Fms-like tyrosine kinase 3; TP53, tumor protein 53; STK11, serine/threonine kinase 11.

mutation in HRAS was detected in the cultured CTCs and the primary tumor tissues (Table III). Similarly, $60 \%$ of the novel mutations were identified in the cultured CTCs and the primary tumor tissues (Table IV). Although the cultured CTCs obtained from patient AMC-15-06 did not possess mutations that have been identified in the COSMIC database that were also detected in the primary tumor tissue, $80 \%$ of novel mutations were identified in the cultured CTCs and the primary tumor tissues (data not shown).

\section{Discussion}

It has been previously reported that CTCs retain the genomic characteristics of the primary tumor. Therefore, CTCs may be used as a substitute for tissue biopsy to evaluate drug responsiveness and predict an optimal therapy $(7,8)$. The authors of the current study performed cancer gene panel analyses using uncultured CTCs (Lee et al, unpublished), which indicated that CTCs are rare, but may be optimal in number for molecular analysis without culturing. However, the expansion of the CTC sample is required for chemosensitivity assays and patient-derived xenograft (PDX) models.

This novel methodology is able to provide sufficient cell numbers for the isolation and culture of CTCs. The number of EpCAM-positive cells ranged from 35 to $86 \%$ of the total cells that were obtained using the culture method and the final number of cultured cells was between $4 \times 10^{5}$ and $8 \times 10^{5}$ (Table I). The cells were cultured until there were $>1 \times 10^{5} \mathrm{CTCs}$ and these cells were used for cancer gene panel analysis. Furthermore, the cultured CTCs may be used in a chemosensitivity assay and in the PDX model of breast cancer. The number of CTCs may have been underestimated in the current study, as the described method was unable to detect mesenchymal CTCs that may have undergone the epithelial to mesenchymal transition (23).

Mutations in PDGFRA, MET, PTEN, HRAS, SMARCB1, $C D K N 2 A$ and $M L H 1$ were identified from the genomic analysis of cultured CTCs in the current study. Mutations in these genes have previously been identified in breast tumor tissues (24-26), and this may demonstrate that cultured CTCs maintain genetic characteristics that are similar to those detected in the primary tumor tissues. PDGFRA and $H R A S$, which were mutated in $3 / 6$ of the cultured CTC samples, are established to be associated with breast cancer progression (25-27).

Furthermore, the analyses of the genomic profiles of primary tumor tissues and those of the corresponding cultured CTCs identified that a large portion of mutations that were detected in CTCs was also detected in the primary tumor tissues. Although the cultured CTCs obtained from patient AMC-15-06 did not have any of the COSMIC database identified mutations also identified in the primary tumor tissue, a mutation of HRAS was detected in CTCs of this patient that has previously been reported to be associated with breast cancer recurrence and metastasis $(27,28)$.

In conclusions, the evaluation of whether cultured CTCs maintain the genomic characteristics of the primary tumor may be the first step in the application of cultured CTCs to predict an effective treatment for a patient with breast cancer. In the present study, CTCs were isolated and cultured effectively, and genomic analysis was performed on them. It was also demonstrated that cultured CTCs may maintain a similar 
genomic profile compared with primary tumor tissues and this suggests that the use of cultured CTCs may provide a novel approach for breast cancer diagnosis and treatment.

\section{Acknowledgements}

The current study was supported by a grant from the National Research and Development Program, Ministry of Trade, Industry and Energy, Republic of Korea (grant no. 10045947). The authors would like to thank Enago (www.enago.kr.com) for the English language review.

\section{Conflict of Interest}

The authors wish to declare that Eunjoo Hwang, Ji-Hyun Uh, Hye Seon Lee, Cham Han Lee, Soo Jeong Lee, Sung Ho Choi, Myoung Shin Kim, Jinseon Lee and Byung Hee Jeon are affiliated with Cytogen Inc. and the kits used in this study were supplied by Cytogen Inc.

\section{References}

1. Ashworth TR: A case of cancer in which cells similar to those in the tumors were seen the blood after death. Aust Med J 14: $146-149,1869$

2. Aceto N, Bardia A, Miyamoto DT, Donaldson MC, Wittner BS, Spencer JA, Yu M, Pely A, Engstrom A, Zhu H, et al: Circulating tumor cell clusters are oligoclonal precursors of breast cancer metastasis. Cell 158: 1110-1122, 2014

3. Cristofanilli M, Hayes DF, Budd GT, Ellis MJ, Stopeck A, Reuben JM, Doyle GV, Matera J, Allard WJ, Miller MC, et al: Circulating tumor cells: A novel prognostic factor for newly diagnosed metastatic breast cancer. J Clin Oncol 23: 1420-1430, 2005.

4. Markiewicz A, Książkiewicz M, Wełnicka-Jaśkiewicz M, Seroczyńska B, Skokowski J, Szade J and Żaczek AJ: Mesenchymal phenotype of CTC-enriched blood fraction and lymph node metastasis formation potential. PLoS One 9: e93901, 2014.

5. Marchetti A, Del Grammastro M, Felicioni L, Malatesta S, Filice G, Centi I, De Pas T, Santoro A, Chella A, Brandes AA, et al: Assessment of EGFR mutations in circulating tumor cell preparations from NSCLC patients by next generation sequencing: Toward a real-time liquid biopsy for treatment. PLoS One 9: e103883, 2014

6. Marrinucci D, Bethel K, Luttgen M, Bruce RH, Nieva J and Kuhn P: Circulating tumor cells from well-differentiated lung adenocarcinoma retain cytomorphologic features of primary tumor type. Arch Pathol Lab Med 133: 1468-1471, 2009.

7. van de Stolpe A, Pantel K, Sleijfer S, Terstappen LW and den Toonder JM: Circulating tumor cell isolation and diagnostics: Toward routine clinical use. Cancer Res 71: 5955-5960, 2011.

8. Giuliano M, Giordano A, Jackson S, De Giorgi U, Mego M, Cohen EN, Gao H, Anfossi S, Handy BC, Ueno NT, et al: Circulating tumor cells as early predictors of metastatic spread in breast cancer patients with limited metastatic dissemination. Brest Cancer Res 16: 440, 2014.

9. Torre LA, Bray F, Siegel RL, Ferlay J, Lortet-Tieulent J and Jemal A: Global cancer statistics, 2012. CA Cancer J Clin 65 87-108, 2015

10. Lorusso $G$ and Rüegg C: New insights into the mechanisms of organ-specific breast cancer metastasis. Semin Cancer Biol 22 226-233, 2012.

11. Cardoso F, Harbeck N, Fallowfield L, Kyriakides S and Senkus E; ESMO Guidelines Working Group: Locally recurrent or metastatic breast cancer: ESMO clinical practice guidelines for diagnosis, treatment and follow-up. Ann Oncol 23 (Suppl 7): vii11-vii19, 2012.
12. Suzuki M and Tarin D: Gene expression profiling of human lymph node metastases and matched primary breast carcinomas: Clinical implications. Mol Oncol 1: 172-180, 2007.

13. Giuliano M, Giordano A, Jackson S, De Giorgi U, Mego M, Cohen EN, Gao H, Anfossi S, Handy BC, Ueno NT, et al: Circulating tumor cells as early predictors of metastatic spread in breast cancer patients with limited metastatic dissemination. Breast Cancer Res 16: 440, 2014.

14. Rack B, Schindlbeck C, Jückstock J, Andergassen U, Hepp P, Zwingers T, Friedl TW, Lorenz R, Tesch H, et al: Circulating tumor cells predict survival in early average-to-high risk breast cancer patients. J Natl Cancer Inst 106: pii: dju066, 2014.

15. Bidard FC, Fehm T, Ignatiadis M, Smerage JB, Alix-Panabières C, Janni W, Messina C, Paoletti C, Müller V, Hayes DF, et al: Clinical application of circulating tumor cells in breast cancer: Overview of the current interventional trials. Cancer Metastasis Rev 32: 179-188, 2013.

16. Nadal R, Lorente JA, Rosell R and Serrano MJ: Relevance of molecular characterization of circulating tumor cells in breast cancer in the era of targeted therapies. Expert Rev Mol Diagn 13: 295-307, 2013.

17. Franken B, de Groot MR, Mastboom WJ, Vermes I, van der Palen J, Tibbe AG and Terstappen LW: Circulating tumor cells, disease recurrence and survival in newly diagnosed breast cancer. Breast Cancer Res 14: R133, 2012.

18. Cristofanilli M, Budd GT, Ellis MJ, Stopeck A, Matera J, Miller MC, Reuben JM, Doyle GV, Allard WJ, Terstappen LW and Hayes DF: Circulating tumor cells, disease progression, and survival in metastatic breast cancer. N Engl J Med 351: 781-791, 2004.

19. Fernandez SV, Bingham C, Fittipaldi P, Austin L, Palazzo J, Palmer G, Alpaugh K and Cristofanilli M: TP53 mutations detected in circulating tumor cells present in the blood of metastatic triple negative breast cancer patients. Breast Cancer Res 16: 445, 2014.

20. Yu M, Stott S, Toner M, Maheswaran S and Haber DA: Circulating tumor cells: Approaches to isolation and characterization. J Cell Biol 192: 373-382, 2011.

21. Edge SB and Compton CC: The American Joint Committee on Cancer: The 7th Edition of the AJCC Cancer Staging Manual and the Future of TNM. Ann Surg Oncol 17: 1471, 2010.

22. Kim EH, Lee JK, Kim BC, Rhim SH, Kim JW, Kim KH, Jung SM, Park PS, Park HC, Lee J and Jeon BH: Enrichment of cancer cells from whole blood using a microfabricated porous filter. Anal Biochem 440: 114-116, 2013

23. Gorges TM, Tinhofer I, Drosch M, Röse L, Zollner TM, Krahn T and von Ahsen O: Circulating tumour cells escape from EpCAM based detection due to epithelial-to mesenchymal transition. BMC Cancer 12: 178, 2012

24. Tung N, Battelli C, Allen B, Kaldate R, Bhatnagar S, Bowles K, Timms K, Garber JE, Herold C, Ellisen L, et al: Frequency of mutations in individuals with breast cancer referred for BRCA1 and BRCA2 testing using next-generation sequencing with a 25-gene panel. Cancer 121: 25-33, 2015

25. Inês $C$, Fernanda M, Albino M, Rui MR and Fernando S: Overexpression of platelet-derived growth factor receptor alpha in breast cancer is associated with tumour progression. Breast Cancer Res 7: R788-R795, 2005.

26. Fernández-Medarde A and Santos E: Ras in cancer and developmental diseases. Genes Cancer 2: 344-358, 2011.

27. Yong HY, Hwang JS, Son H, Park HI, Oh ES, Kim HH, Kim DK, Choi WS, Lee BJ, Kim HR and Moon A: Identification of $\mathrm{H}$-Ras-specific motif for the activation of invasive signaling program in human breast epithelial cells. Neoplasia 13: 98-107, 2011.

28. Watson DM, Elton RA, Jack WJ, Dixon JM, Chetty U and Miller WR: The H-ras oncogene product $\mathrm{p} 21$ and prognosis in human breast cancer. Breast Cancer Res Treat 17: 161-169, 1991. 